\title{
Predatory publishers and bad journalism
}

\author{
Perspective
}

\author{
Pardis Tabaee Damavandi \\ Queen Mary University of London, Mile End Road, London, London, UK. \\ p.tabaee@qmul.ac.uk
}

Jeffrey Beall ${ }^{1}$ made in 2012 a list of potential predatory publishers which were mainly linked to open-access journals what with these journals were selecting their 'preys' by approaching a random researcher's contact details publicly posted in successful papers. Almost all the publishers exposed in the list were predatory; by the term 'predatory' Bohannon and other recent reports ${ }^{2}$ meant that money being taken to grant publication is not adequately being spent, because once the manuscript is accepted by a predatory journal, no advertising occurs, nor do these journals offer any peer-review. At times, excellent peer reviewers were unawarely picked in an equally predatory fashion to review for such journals, but again the rights of the author that derive from paying a publishing fee were not being abided by.

The points made by both Beall and Bohannon are excellent, however, with the advent of even more 'beguiling' publishers, i.e. some predatory preprint servers, the difficulties undiscussed during 'old-fashioned' predatory publishing 'times' remain unaddressed. Those problems are raised in this short perspective.

At first glance, General Data Protection Regulation consent compliance seems usually lacking in predatory publishing behaviour, therefore increasing compliance towards obtaining GDPR authorisation may be beneficial. This requirement has recently been extended to non-profit organisations in the USA, whereas in Europe non-profit organisations are not required to request author's approval. With author's approval it is argued that the minimum authorisation should be provided by the owner or owners of the manuscript's intellectual property. GDPR sensitive data include not only photos, but also email addresses, names, banking information and addresses. When consent is not given, or is given without awareness, retraction should be offered, regardless of the submission involving a journal or a preprint journal. Predatory preprint servers do not usually arrange for this option and abuse a position of trust in the organisation or popularity by extension to social media to retaliate against the author who requested retraction post-unapproved publication. An example is the preprint server Biorxiv ${ }^{3}$, which requests submissions via transfer from other journals without asking formal approval by the author, and refusing retraction post-request by adopting retaliatory endeavours. Although this preprint server self-defines its organisation as non-profit, the behaviours conceal something more 'sinister'. Plagiarism happens in the moment Biorxiv publishes the work onsite and then removes it upon suggestion for unauthorised consent. It 
consequently transpires that this 'negative aspect' to predatory publishing becomes harder to prove due to the retributive behaviour which disregards the author's interest. This approach is not just unethical but also constitutes bad journalism.

The second point being hereby addressed is thus what good journalism necessitates. According to Bernstein ${ }^{4}$ free press and good journalism are about the motivation 'on obtaining a best version of the truth' and publicising it. This involves basic gathering of information, graceful written communication, accuracy and truthfulness, novelty and originality as well as extended knowledge. Contrarily, a bad reporter is defined as a man without quality who writes falsehoods for his own profit; the bad reporter in question evidently supports bad journalism ${ }^{5}$. An additional characteristic of good journalism is the art of persuasion whose concept was introduced by Cicero ${ }^{6-7}$, and explored by Machiavelli ${ }^{8}$ in his Prince, nonetheless embellished persuasion is solely used to express truth, rather than to 'lighten the load'.

Another indication of good journalism is the disclosure of conflicts of interest, exemplifying research integrity, particularly in the context of scientific journalism.

Journalism in its purest form could also be associated with what Rilke denotes in the Letters to a Young Poet ${ }^{9}$; a journalist as a writer is someone who carries the feeling or wish in his 'innermost being'. Implicit in this statement lie the concepts of novelty and originality, but also of truthfulness and honesty.

Finally, some journalists contend that deontological reporting is debateable and does not constitute proper scientific journalism, though, looking more closely, abiding to established guidelines is not about assuming a conservative approach towards publishing, but can be a very helpful step in guiding less experienced reporters who are just beginning to launch a career in the field.

\section{Bibliography}

1. Beall J., Predatory Publishers are corrupting open access, Nature. 2012; 489(7415): 179.

2. Bohannon J., Who's afraid of Peer Review?, Science. 2013; 342(6154): 60-65.

3. Learn J. R., What bioRxiv's first 30,000 preprints reveal about biologists, Nature, 2019.

4. Greenslade R., Bernstein: what makes good journalism, The Guardian. 2012.

5. Sanders K., 2003, Ethics and Journalism?, $1^{\text {st }}$ Edition, London, Sage Publications Ltd.

6. Cicero M. T., $55 \mathrm{BCE}$, De Oratore.

7. Quintilianus M. F., 90-96 AD, Institutio Oratoria.

8. Machiavelli N., 1532, The Prince, $1550^{\text {th }}$ Edition, Italy, Antonio Blado D'Asola.

9. Rilke R. M., 1929, Letters to a Young Poet, Paris, France.

The authors are the legal and entitled owners of the property in reference and nobody else can legally take, use, claim ownership, republish, reprint, create or generate the content without their written and legal consent. 